\title{
Carbon dioxide hydrogenation to aromatic hydrocarbons by using an iron/iron oxide nanocatalyst
}

\author{
Hongwang Wang ${ }^{* 1}$, Jim Hodgson ${ }^{1}$, Tej B. Shrestha ${ }^{2}$, Prem S. Thapa ${ }^{3}$, \\ David Moore ${ }^{3}$, Xiaorong Wu ${ }^{4}$, Myles Ikenberry ${ }^{5}$, Deryl L. Troyer $^{2}$, \\ Donghai Wang ${ }^{4}$, Keith L. Hohn ${ }^{5}$ and Stefan H. Bossmann ${ }^{* 1}$
}

\section{Full Research Paper}

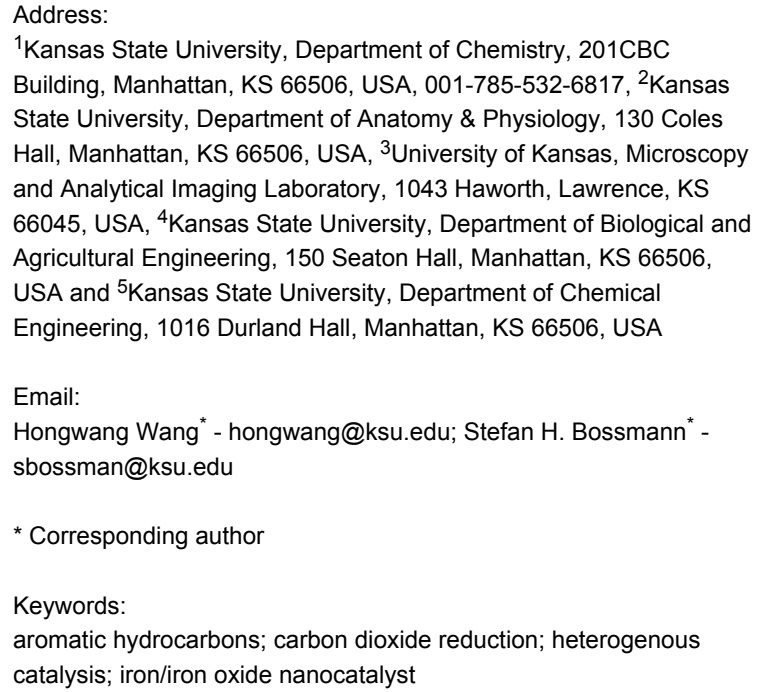

${ }^{1}$ Kansas State University, Department of Chemistry, 201CBC Building, Manhattan, KS 66506, USA, 001-785-532-6817, ${ }^{2}$ Kansas State University, Department of Anatomy \& Physiology, 130 Coles Hall, Manhattan, KS 66506, USA, ${ }^{3}$ University of Kansas, Microscopy and Analytical Imaging Laboratory, 1043 Haworth, Lawrence, KS 66045, USA, ${ }^{4}$ Kansas State University, Department of Biological and Agricultural Engineering, 150 Seaton Hall, Manhattan, KS 66506 , USA and ${ }^{5}$ Kansas State University, Department of Chemical Engineering, 1016 Durland Hall, Manhattan, KS 66506, USA

Email:

Hongwang Wang* - hongwang@ksu.edu; Stefan H. Bossmann* sbossman@ksu.edu

${ }^{*}$ Corresponding author

Keywords:

aromatic hydrocarbons; carbon dioxide reduction; heterogenous catalysis; iron/iron oxide nanocatalyst

\begin{abstract}
The quest for renewable and cleaner energy sources to meet the rapid population and economic growth is more urgent than ever before. Being the most abundant carbon source in the atmosphere of Earth, $\mathrm{CO}_{2}$ can be used as an inexpensive $\mathrm{C} 1$ building block in the synthesis of aromatic fuels for internal combustion engines. We designed a process capable of synthesizing benzene, toluene, xylenes and mesitylene from $\mathrm{CO}_{2}$ and $\mathrm{H}_{2}$ at modest temperatures $\left(T=380\right.$ to $\left.540{ }^{\circ} \mathrm{C}\right)$ employing $\mathrm{Fe} / \mathrm{Fe}_{3} \mathrm{O}_{4}$ nanoparticles as catalyst. The synthesis of the catalyst and the mechanism of $\mathrm{CO}_{2}$-hydrogenation will be discussed, as well as further applications of $\mathrm{Fe} / \mathrm{Fe}_{3} \mathrm{O}_{4}$ nanoparticles in catalysis.
\end{abstract}

\section{Introduction}

The diminishing fossil reserves and the ever-increasing $\mathrm{CO}_{2}$ emissions have been of great concern amongst the scientific community. Since the industrial revolution, a significant

\author{
Beilstein J. Nanotechnol. 2014, 5, 760-769. \\ doi:10.3762/bjnano.5.88 \\ Received: 11 March 2014 \\ Accepted: 30 April 2014 \\ Published: 02 June 2014 \\ Associate Editor: J. J. Schneider \\ (C) 2014 Wang et al; licensee Beilstein-Institut. \\ License and terms: see end of document.
}


changes [1-3]. As a result, the quest for renewable and cleaner energy sources to meet the rapid population and economic growth is more urgent than ever before. Being the most abundant carbon source in the atmosphere of Earth, $\mathrm{CO}_{2}$ can be used as a cheap and non-toxic $\mathrm{C} 1$ building block in many chemical processes [4-7]. To achieve this goal, $\mathrm{CO}_{2}$ should come from the atmosphere and $\mathrm{H}_{2}$ should be created by using solar energy from water [8-10]. Iron-based heterogeneous catalysts have been intensively studied for $\mathrm{CO}_{2}$ hydrogenation reactions. Earlier research showed that bulk iron and iron oxides catalyze $\mathrm{CO}_{2}$ hydrogenation, producing mainly methane. These catalysts were rapidly deactivated due to carbon deposition [11,12]. Doping with promoters such as potassium [13-18], manganese [19-21] and copper [22] had significant effect on both the reactivity and selectivity of the iron-based catalysts. Higher olefins and aliphatic hydrocarbons, as well as improved $\mathrm{CO}_{2}$ conversion, were achieved. $\mathrm{Al}_{2} \mathrm{O}_{3}$ was found to be an excellent structural promoter to sustain the catalyst activity of iron-based catalysts by preventing sintering of active particles during the reaction $[23,24]$. When using zeolites as solid supports, the product distribution was highly dependent on the structure and acidity of the zeolites [25-27]. Iron-zeolite composites were reported as dual functional catalysts, which promoted multistep $\mathrm{CO}_{2}$ hydrogenation reactions [28].

In spite of all the efforts to date, the direct formation of aromatic hydrocarbons in a one-step reaction from carbon dioxide, without forming aliphatic hydrocarbons first, remained elusive. Here, we report the selective formation of aromatic hydrocarbons from $\mathrm{CO}_{2}$ and $\mathrm{H}_{2}$ via a novel iron nanocatalyst.

\section{Results and Discussion Advantages of nanomaterials as heteroge- neous catalysts}

Due to their unique properties, such as a large surface-area-tovolume ratio, nanomaterials have attracted massive attention in catalysis applications [29-31]. Using newly developed in-situ characterization technologies, detailed atomic- and molecularlevel information of the catalytic reaction mechanisms has been revealed [32,33]. Elegant protocols to synthesize monodispersed composite iron-based or iron-containing nanomaterials with controlled size and shape have been developed [34-41]. The application of such materials in cancer diagnosis and cancer treatment, such as MRI and magnetic hyperthermia are intensively studied [42-44]. The use of iron-containing nanomaterials as catalysts for the methanol oxidation reaction [45], and oxygen reduction reaction [46-48] have been reported.

\section{Synthesis of $\mathrm{Fe} / \mathrm{Fe}_{3} \mathrm{O}_{4}$ nanoparticles}

Here we report the selective formation of aromatic hydrocarbons from $\mathrm{CO}_{2}$ hydrogenation reactions catalyzed by an
$\mathrm{Fe} / \mathrm{Fe}_{3} \mathrm{O}_{4}$ nanocatalyst. Recently, Sun's group reported a facile method for synthesizing highly crystalline $\mathrm{Fe} / \mathrm{Fe}_{3} \mathrm{O}_{4}$ nanoparticles [49]. These nanoparticles were found to be robust against deep oxidation because of the formation of a protective crystalline $\mathrm{Fe}_{3} \mathrm{O}_{4}$ shell upon the direct oxidation of the bcc-Fe core. The synthesis of the $\mathrm{Fe} / \mathrm{Fe}_{3} \mathrm{O}_{4}$ nanoparticles was slightly modified and scaled up by a factor of three (see Experimental section). To avoid violent $\mathrm{Fe}(\mathrm{CO})_{5}$ reflux, three portions of $0.70 \mathrm{~mL} \mathrm{Fe}(\mathrm{CO})_{5}$ were added to the mixture of the ligands oleylamine and hexadecylammonium hydrochloride $(\mathrm{HDA} \cdot \mathrm{HCl})$ and solvent (1-octadecene, ODE) every $20 \mathrm{~min}$ at $180^{\circ} \mathrm{C}$ instead of adding the iron precursor all at one time. After the third addition, the reaction mixture was kept for 40 min at $180{ }^{\circ} \mathrm{C}$ to permit a controlled nanoparticle growth, and then allowed to cool down to rt. After decanting of the supernatant, the nanoparticles that were accumulated on the stirring bar were thoroughly washed with hexane and then ethanol (sonication) to remove the free ligands. The NPs were dried in high vacuum, and the yield based on iron was found to be $95 \%$.

\section{$\mathrm{CO}_{2}$ hydrogenation reaction}

The $\mathrm{Fe} / \mathrm{Fe}_{3} \mathrm{O}_{4}$ nanoparticle-catalyzed $\mathrm{CO}_{2}$ hydrogenation reaction was performed in a custom-built reactor (see details in the Experimental section). $50 \mathrm{mg} \mathrm{Fe} / \mathrm{Fe}_{3} \mathrm{O}_{4}$ nanoparticles were subjected to a continuous supply of $(1: 1 \mathrm{~mol} / \mathrm{mol}) \mathrm{CO}_{2} / \mathrm{H}_{2}$ atmosphere at $1 \mathrm{~atm}$ pressure. Gas samples were withdrawn from the reactor and analyzed by GC-MS during the reaction. The GC profile of the products during the reaction is shown in Figure 1. Upon heating from $\mathrm{rt}$ to $400{ }^{\circ} \mathrm{C}$, traces of butane (2.881 $\mathrm{min})$, benzene (4.135 $\mathrm{min}$ ) and toluene (5.819 $\mathrm{min}$ ) were observed, together with a major peak (2.989 $\mathrm{min}$ ) and minor peak $(5.765 \mathrm{~min})$ in the GC profile corresponding to $\mathrm{m} / \mathrm{z} 68$ and 71. We have assigned these two species to carbon suboxide $\left(\mathrm{C}_{3} \mathrm{O}_{2}\right)$ and its partially reduced form $\left(\mathrm{C}_{3} \mathrm{O}_{2} \mathrm{H}_{3}\right)$. Upon raising the temperature to $440{ }^{\circ} \mathrm{C}$, three new peaks appeared at $7.915 \mathrm{~min}, 8.100 \mathrm{~min}, 8.688 \mathrm{~min}$, all of these correspond to $\mathrm{m} / \mathrm{z}$ 106. By comparing with commercially available standard samples, these three peaks were identified as $m$-xylene, $p$-xylene and $o$-xylene, respectively. The reaction temperature was raised at a rate of $1{ }^{\circ} \mathrm{C} / \mathrm{min}$ afterwards, and gas samples were subjected to GC-MS analysis every $20 \mathrm{~min}$. We found that, with the increase of reaction temperature, the intensity of the peak at $2.989 \min \left(\mathrm{C}_{3} \mathrm{O}_{2}\right)$, decreased gradually. At the same time, the intensity of the benzene peak (4.135 min) and toluene peak $(5.819 \mathrm{~min})$ increased. At $480{ }^{\circ} \mathrm{C}$, the peak at $2.989 \mathrm{~min}$ $\left(\mathrm{C}_{3} \mathrm{O}_{2}\right)$ disappeared completely, while the peak at $5.765 \mathrm{~min}$ $\left(\mathrm{C}_{3} \mathrm{O}_{2} \mathrm{H}_{3}\right)$ still persisted until the temperature reached $500{ }^{\circ} \mathrm{C}$. Further increasing temperature to $520^{\circ} \mathrm{C}$ led to the decrease of the xylene peaks. The decrease of the toluene peak and the increase of the benzene peak were observed while keeping the reaction at $520^{\circ} \mathrm{C}$ for $40 \mathrm{~min}$. A heterogeneous rate constant of 


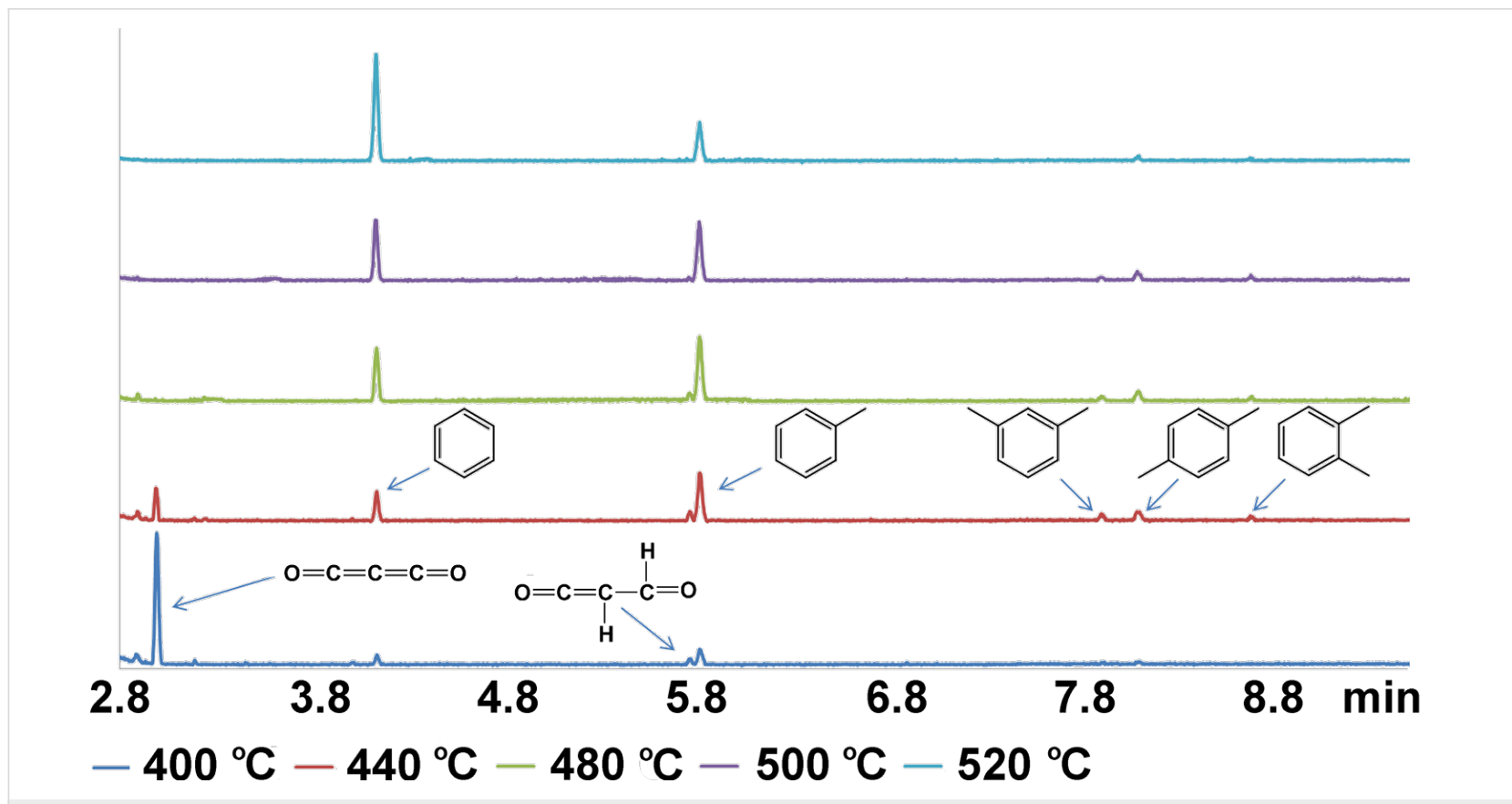

Figure 1: $\mathrm{GC}$ profile of the products formed during $\mathrm{CO}_{2}$ hydrogenation at different temperatures.

$0.00113 \mathrm{~s}^{-1} \cdot \mathrm{g}^{-1}$ for the consumption of $\mathrm{CO}_{2}$ at $400{ }^{\circ} \mathrm{C}$ was calculated from the kinetic data shown in the Supporting Information File 1 (Figure S1). The catalyst was reused 10 times. No decrease of the catalytic activity was observed. This observation is based on the consumption efficiency of $\mathrm{CO}_{2}$ from the gas phase and product analysis by GC-MS.

\section{Characterization of the catalysts (TEM, HRTEM,} XRD, XPS)

The TEM image reveals that the newly synthesized $\mathrm{Fe} / \mathrm{Fe}_{3} \mathrm{O}_{4}$ nanoparticles are roughly spherical with a core/shell structure (Figure 2). The mean core diameter is $12 \mathrm{~nm}$, and the shell thickness is $2 \mathrm{~nm}$. HRTEM indicate that each $\mathrm{Fe} / \mathrm{Fe}_{3} \mathrm{O}_{4}$ nanoparticle assumes polycrystalline structure with rigid edges.

TEM images (Figure 3) of recycled catalyst after 10 runs of reactions shows that the nanoparticles fused to larger irregularly shaped particles with crystalline substructures on the surface. HRTEM reveal that the substructure is polycrystalline.

The XRD patterns of the $\mathrm{Fe} / \mathrm{Fe}_{3} \mathrm{O}_{4}$ nanoparticles as a function of the number of catalytic runs is shown in Figure 4. The XRD characterization of the freshly prepared $\mathrm{Fe} / \mathrm{Fe}_{3} \mathrm{O}_{4}$ nanoparticles confirmed the crystalline structure as previously reported [50]:

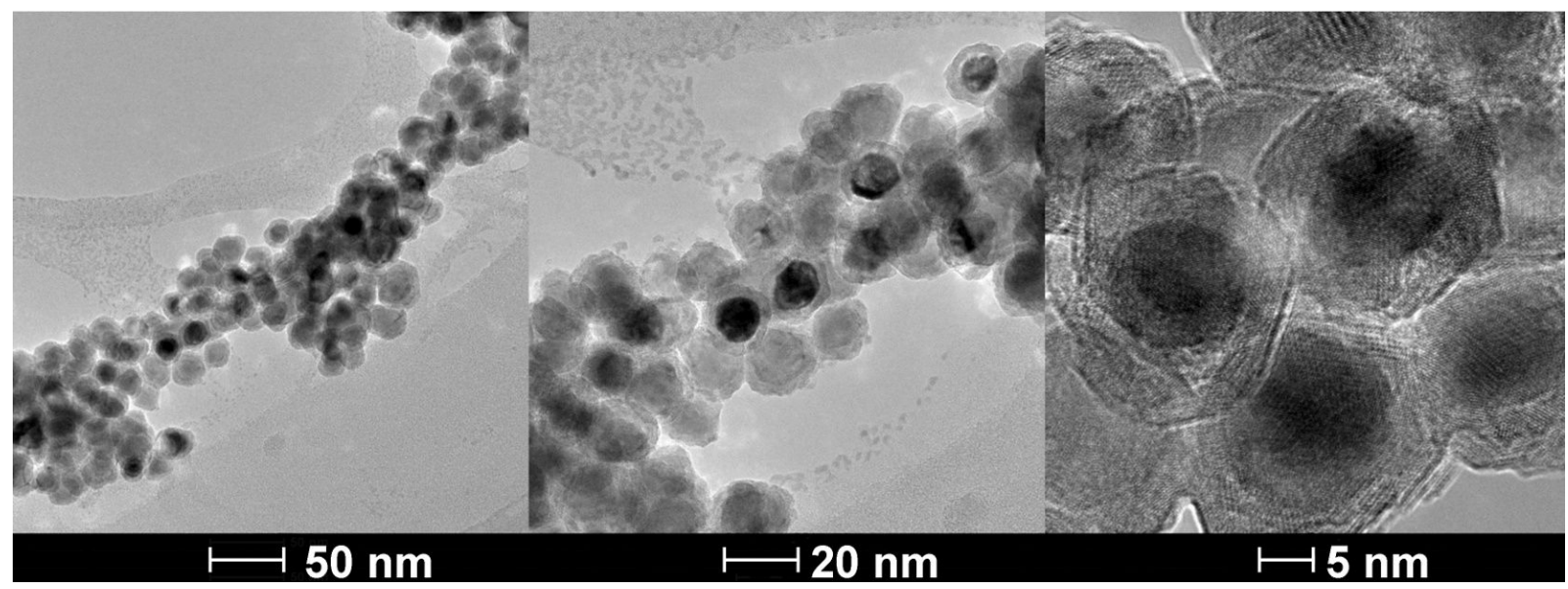

Figure 2: TEM and $\mathrm{HRTEM}$ of $\mathrm{Fe} / \mathrm{Fe}_{3} \mathrm{O}_{4}$ nanoparticles prepared by thermal decomposition of $\mathrm{Fe}(\mathrm{CO})_{5}$ in the presence of oleylamine and $\mathrm{HDA} \cdot \mathrm{HCl}$. 


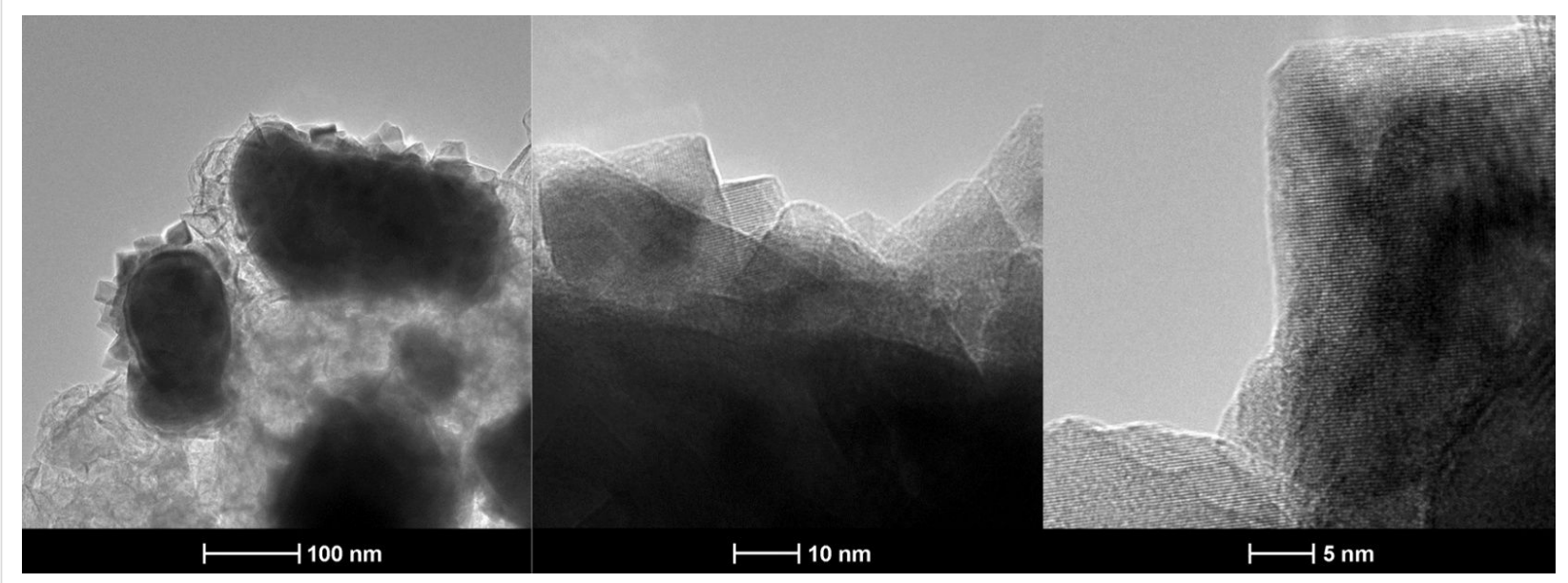

Figure 3: TEM and HRTEM of $\mathrm{Fe} / \mathrm{Fe}_{3} \mathrm{O}_{4}$ nanoparticles prepared by thermal decomposition of $\mathrm{Fe}(\mathrm{CO})_{5}$ in the presence of oleylamine and $\mathrm{HDA} \cdot \mathrm{HCl}$ after performing 10 catalytic cycles.

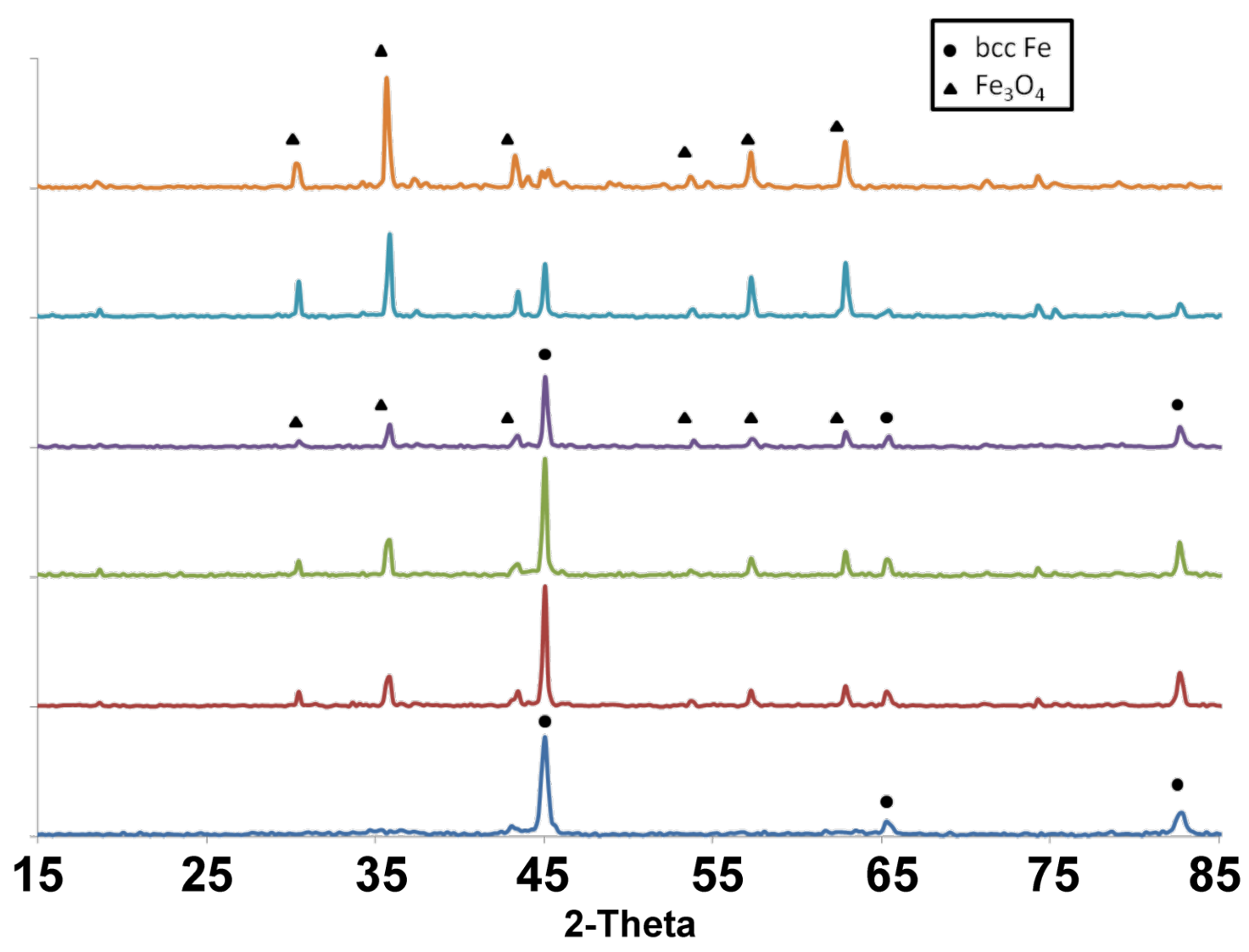

\section{- before catalysis - run 1 - run $5-$ run $10-$ run $15-$ run 18}

Figure 4: XRD patterns of the $\mathrm{Fe} / \mathrm{Fe}_{3} \mathrm{O}_{4}$ nanoparticles as a function of catalytic run $\left(2 \mathrm{~h}\right.$ at $\left.400{ }^{\circ} \mathrm{C}\right)$.

Only the (110) and (200) peaks corresponding to bcc-Fe are observed. XRD characterization of the recycled nanoparticles after each run of catalysis demonstrated that the crystallinity of the catalyst changed from bcc-Fe to a mixture of bcc-Fe and $\mathrm{Fe}_{3} \mathrm{O}_{4}$ (run 1 to run 17), and eventually to $\mathrm{Fe}_{3} \mathrm{O}_{4}$ (after run 18 of catalysis reaction). The observed conversion of bcc-Fe to 
$\mathrm{Fe}_{3} \mathrm{O}_{4}$ in the presence of $\mathrm{H}_{2} \mathrm{O}$ at the reported temperature is in agreement with literature findings [51].

\section{XPS analysis of the surface of the catalyst}

The XPS analysis [52] of the fresh catalyst (Table 1) is consistent with iron oxide that is covered by a molecular layer of oleylamine/HDA $\cdot \mathrm{HCl}$. XPS indicates a decreased carbon composition after the first five runs, followed by an increased carbon loading from run 5 through run 10, as shown in Figure 5. This is consistent with the hypothesis that the surface loses the coordinating HDA ligands during the initial runs. The concurrent loss of nitrogen and chlorine is consistent with this mechanistic assumption. The lost carbon by displacement of HDA is overcompensated during runs $6-10$ by the deposition of carbon from the catalytic reaction. Carbon deposition is typically observed during the reaction of carbon dioxide or carbon monoxide with molecular hydrogen at iron oxide [53]. Interestingly, carbon can be (partially) removed from the surface by hydrogen, as the hydrogenation after run 6 indicates.

Table 1: Iron, oxygen, nitrogen, carbon and chloride content at the catalyst surface, as determined by XPS, as a function of catalytic runs.

\begin{tabular}{llllll} 
sample & Fe & O & N & C & Cl \\
\hline fresh catalyst & 3.4 & 30 & 2.5 & 60.8 & 3.3 \\
5 runs & 11.8 & 38.5 & 1.9 & 46.7 & 1.2 \\
10 runs & 3.2 & 12 & 1.6 & 82.8 & 0.4 \\
6 runs, followed by & 12.9 & 43.8 & 1.3 & 41.2 & 0.8 \\
$\mathrm{H}_{2}$ reduction & & & & &
\end{tabular}

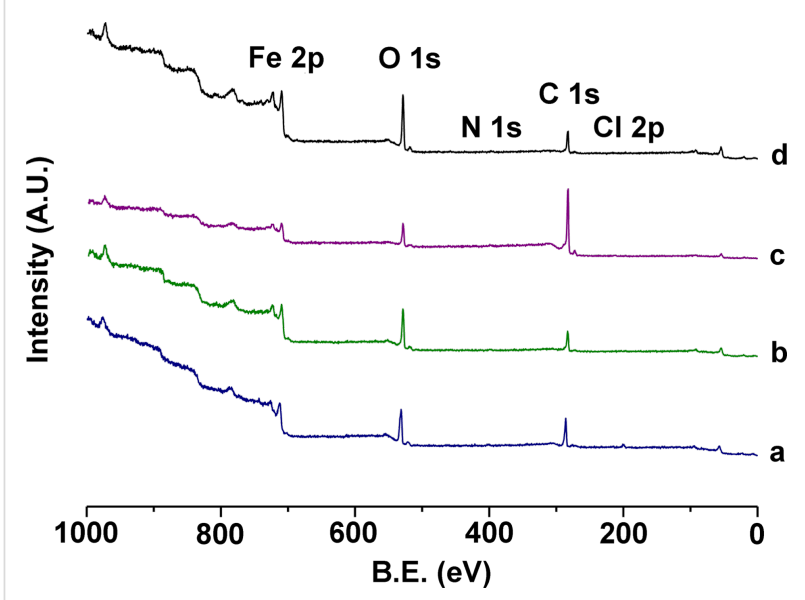

Figure 5: XPS surveys of the catalyst: a) as prepared with HDA synthesis, b) after 5 runs, c) after 10 runs, d) after 6 runs, followed by $\mathrm{H}_{2}$ reduction. Catalytic runs were performed for $2 \mathrm{~h}$ at $400{ }^{\circ} \mathrm{C}$.
The Fe $2 p$ region (Figure 6) yields information about the oxidation state of iron in the particles. The small peak around $706.5 \mathrm{eV}$, which indicates $\mathrm{Fe}(0)$ is present in the fresh catalyst, but is absent after the catalyst has undergone 5 runs. It appears again in the sample that was reduced by $\mathrm{H}_{2}$. This indicates that the surface layer of the as-synthesized particles contains a small amount of $\mathrm{Fe}^{0}$ in addition to the $\mathrm{Fe}^{2+}$ and $\mathrm{Fe}^{3+}$, which is in agreement with the literature [54]. However, deconvolution of the $\mathrm{Fe} 2 \mathrm{p}$ region is rather difficult due to the large number of peaks necessary for an accurate curve fitting. From the experimental finding that the catalytic rate of the reaction remains practically unchanged at $0.00113 \pm 0.00005 \mathrm{~s}^{-1} \mathrm{~g}^{-1}$ for the consumption of $\mathrm{CO}_{2}$ at $400{ }^{\circ} \mathrm{C}$, we have concluded that the presence of $\mathrm{Fe}(0)$ is not necessary for the observed formation of aromatic hydrocarbons. This multistep reaction (see below) proceeds apparently at the surface of freshly formed $\mathrm{Fe}_{3} \mathrm{O}_{4}$, which is produced through the reaction of $\mathrm{H}_{2} \mathrm{O}$ with $\mathrm{Fe}(0)$ in the temperature range in which the formation of aromatic hydrocarbons is observed [55].

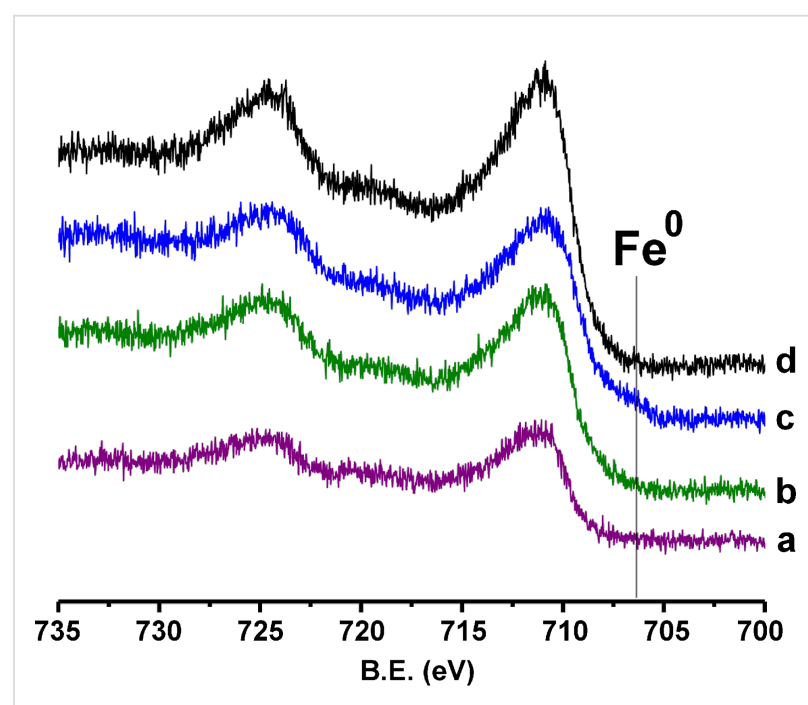

Figure 6: XPS of the Fe $2 p^{3 / 2}$ and Fe $2 p^{1 / 2}$ region for the catalyst: a) after 10 runs, b) after 5 runs, c) as prepared with HDA, d) after 6 runs, followed by $\mathrm{H}_{2}$ reduction.

\section{Reaction mechanism}

It is well accepted that the formation of aliphatic hydrocarbons from iron catalyzed $\mathrm{CO}_{2}$ hydrogenation reactions proceeds through a 2-step reaction process. In the first step, there is conversion of $\mathrm{CO}_{2}$ to $\mathrm{CO}$ via the reverse water-gas shift reaction (RWGS) [56].

$$
\mathrm{CO}_{2}+\mathrm{H}_{2} \rightleftharpoons \mathrm{CO}+\mathrm{H}_{2} \mathrm{O}
$$

In the second step, hydrocarbon chains are built up through the Fischer-Tropsch reaction (FT) [57]. 


\section{$\mathrm{CO}+2 \mathrm{H}_{2} \longrightarrow-\mathrm{CH}_{2}-+\mathrm{H}_{2} \mathrm{O}$}

However, only methane (minor fraction), propane, butane and propanal could be identified as aliphatic products of the reaction of carbon dioxide and hydrogen at $\mathrm{Fe} / \mathrm{Fe}_{3} \mathrm{O}_{4}$ nanocatalysts. Based on these findings and the characterization of the surfaces of the catalyst, we propose the following mechanism for the selective formation of aromatic hydrocarbons in the $\mathrm{Fe} / \mathrm{Fe}_{3} \mathrm{O}_{4}$ nanoparticle catalyzed $\mathrm{CO}_{2}$ hydrogenation reaction. In the first step, the iron nanoparticle catalyzes the reverse water gas shift (RWGS) reaction to produce $\mathrm{CO}$ from $\mathrm{CO}_{2}$, as discussed above [56]. This step is the same as in the Fischer-Tropsch reaction [57]. In the second step of the manifold of reactions leading to aromatic products, the reaction of two CO molecules results in deposition of carbon on the surface of the catalyst and the formation of $\mathrm{CO}_{2}$. This "Boudouard reaction" is well established [53]:

$$
\mathrm{CO}+\mathrm{CO} \longrightarrow \mathrm{C}+\mathrm{CO}_{2}
$$

In the third step, two $\mathrm{CO}$ molecules react stepwise with the freshly deposited carbon on the catalyst to yield carbon suboxide $\left(\mathrm{C}_{3} \mathrm{O}_{2}\right)$.

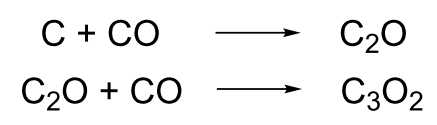

This exothermic reaction has been reported in 1973 by Kammula and Shevlin [58]: $\mathrm{C}_{3} \mathrm{O}_{2}$ has been identified by comparison of the mass spectrum (Supporting Information File 1) with the reference spectrum available from the Wiley collection [59]. $\mathrm{C}_{3} \mathrm{O}_{2}$ is metastable and undergoes rapid polymerization at temperatures above $400{ }^{\circ} \mathrm{C}$ [60]. It is noteworthy that the formation of polymers at the surface of the catalyst was not observed in the reaction system studied here. Instead, $\mathrm{C}_{3} \mathrm{O}_{2}$ is reduced by $\mathrm{H}_{2}$ to $\mathrm{H}_{2} \mathrm{C}_{3} \mathrm{O}_{2}$ (Scheme 1 , see mass spectrum in Supporting Information File 1).

In the fourth step, $\mathrm{H}_{2} \mathrm{C}_{3} \mathrm{O}_{2}$ trimerizes at the surface of $\mathrm{Fe}_{3} \mathrm{O}_{4}$ to the symmetrical 2,4,6-trioxocyclohexane-1,3,5-tricarbaldehyde (Scheme 2).

\begin{abstract}
$\mathrm{O}=\mathrm{C}=\mathrm{C}=\mathrm{C}=\mathrm{O} \underset{\mathrm{Fe}_{3} \mathrm{O}_{4}}{\stackrel{\mathrm{H}_{2}}{\longrightarrow}} \mathrm{O}=\mathrm{C}=\underset{\mathrm{H}}{\stackrel{\mathrm{H}}{\mathrm{H}}}=\mathrm{O}$
Scheme 1: Hydrogenation of carbon suboxide.

$\mathrm{Fe}_{3} \mathrm{O}_{4}$ predominantly grows along the (111) and (001) planes, while (110) planes are less abundant [61]. The (001) plane can be viewed as alternating sequence of one layer with tetrahedrally coordinated Fe cations and a second layer with octahedrally coordinated Fe cations. Both coordination environments of Fe cations have been found at the surface [62-64]. A recent computational study found six possible terminations of the (111) plane. Again, two of them were found to be most stable, featuring either tetrahedrally or octahedrally coordinated Fe cations at the surface. Experimental evidence supporting these predictions is also available [65]. Further HRTEM experiments will have to be conducted to elucidate the exact nature of the active plane in $\mathrm{Fe}_{3} \mathrm{O}_{4}$, which is constantly formed from $\mathrm{Fe}$ and $\mathrm{H}_{2} \mathrm{O}$ under the working conditions of the $\mathrm{CO}_{2} / \mathrm{H}_{2}$ reaction to aromatic hydrocarbons [23].
\end{abstract}

The fifth step consists of the keto-enol tautomerization from 2,4,6-trioxocyclohexane-1,3,5-tricarbaldehyde to 2,4,6-trihydroxybenzene-1,3,5-tricarbaldehyde (Scheme 3). This step is exergonic because of the aromatic resonance energy of the formed triphenol, which is approx. $30-35 \mathrm{~kJ} \cdot \mathrm{mol}^{-1}$ [66].<smiles>C#CC=CC1C(=O)C(C=O)C(=O)C(C=O)C1=O</smiles>

Scheme 3: Keto-enol tautomerism leads to aromatization.

The symmetrical trihydroxybenzene-derivative is then reduced to the principal reaction product mesitylene $\left(\mathrm{C}_{9} \mathrm{H}_{12}\right)$ (Scheme 4).

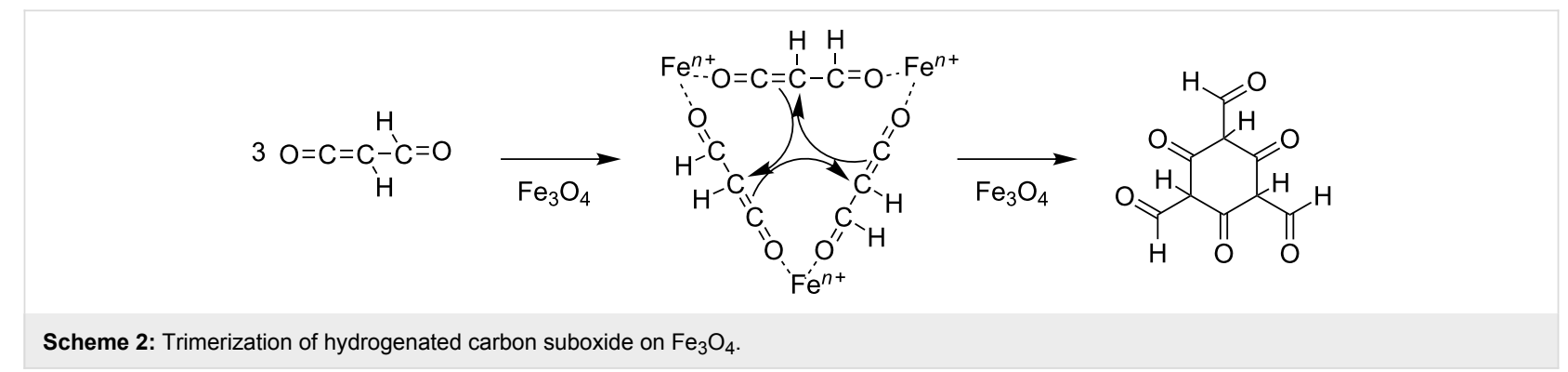


<smiles>Cc1cc(C)cc(C)c1</smiles>

Scheme 4: Reduction of the intermediate phenol derivative to mesitylene.

At high temperature in the presence at $\mathrm{Fe}_{3} \mathrm{O}_{4}$, mesitylene undergoes stepwise demethylation to form xylenes, toluene and finally, benzene (Scheme 5). The byproduct of this reaction consists of a mixture of aliphatic hydrocarbons. Note that the reduction of $\mathrm{C}_{3} \mathrm{O}_{2}$ by $6 \mathrm{H}_{2}$ is also able to form propane, which, therefore, does not necessarily have to come from demethylation processes.

It is noteworthy that all aromatic reaction products (mesitylene, $o-, m$-, and $p$-xylene, toluene and benzene) are high-octane components of gasoline [67]. Therefore, this catalytic reaction is able to transform gaseous hydrogen and carbon dioxide into high-quality fuel, which can be distributed by using the existing distribution infrastructure. Our findings are corroborated by Wright et al. (US patent $4,565,831$ ), in which the authors describe a process for producing a mixture of aliphatic and aromatic hydrocarbons from carbon monoxide and water at modest temperatures on iron/thallium catalysts [68]. Although no mechanisms are discussed, it is of importance that Wright et al. also found that aromatic hydrocarbons are easily formed on $\mathrm{Fe}_{3} \mathrm{O}_{4}$. The latter is formed from $\mathrm{Fe}$ in the presence of $\mathrm{H}_{2} \mathrm{O}$ in the temperature range of interest.
Finally, it should be noted that carbon suboxide undergoes thermolysis to carbon monoxide and dicarbon monoxide $\left(\mathrm{C}_{2} \mathrm{O}\right)$ [69]. Although this process is observed at distinctly higher temperatures in the gas phase, it may also occur at the surface of the catalyst. It is very likely that dicarbon monoxide will then be hydrogenated to ketene $\left(\mathrm{H}_{2} \mathrm{C}=\mathrm{C}=\mathrm{O}\right)$. The presence of ketene would offer a pathway to xylenes, toluene, and benzene without the need to postulate a demethylation mechanism of mesitylene.

\section{Tests of the mechanistic paradigm}

To verify the formation of mesitylene, the $\mathrm{CO}_{2}$ hydrogenation reaction was carried out at $520^{\circ} \mathrm{C}$ using exactly the same conditions as described previously. A peak at 10.417 min, corresponding to $\mathrm{m} / \mathrm{z} 120$ was observed in the GC-MS. This compound was identified as mesitylene by comparing with a standard sample. This proved unambiguously that mesitylene is formed from $\mathrm{CO}_{2}$ and $\mathrm{H}_{2}$ at the surface of the $\mathrm{Fe} / \mathrm{Fe}_{3} \mathrm{O}_{4}$ nanocatalysts.

\section{Product selectivities}

We have calculated the product selectivities, defined as the number of moles of a specific product over the total number of moles of product, based on the GC-MS results obtained at $440{ }^{\circ} \mathrm{C}, 480{ }^{\circ} \mathrm{C}, 500{ }^{\circ} \mathrm{C}$, and $520^{\circ} \mathrm{C}$ and our calibration data using chemical standards. The results obtained for all reaction products that were clearly identified are summarized in Figure 7.

\section{Experimental Synthesis of the $\mathrm{Fe} / \mathrm{Fe}_{3} \mathrm{O}_{4}$ nanocatalysts}

Iron nanoparticles were prepared with slight modification of a literature procedure described by Lacroix et al [49]. A $250 \mathrm{~mL}$, three-necked, round-bottom flask equipped with a magnetic stir<smiles>Cc1ccc(C)cc1</smiles> 


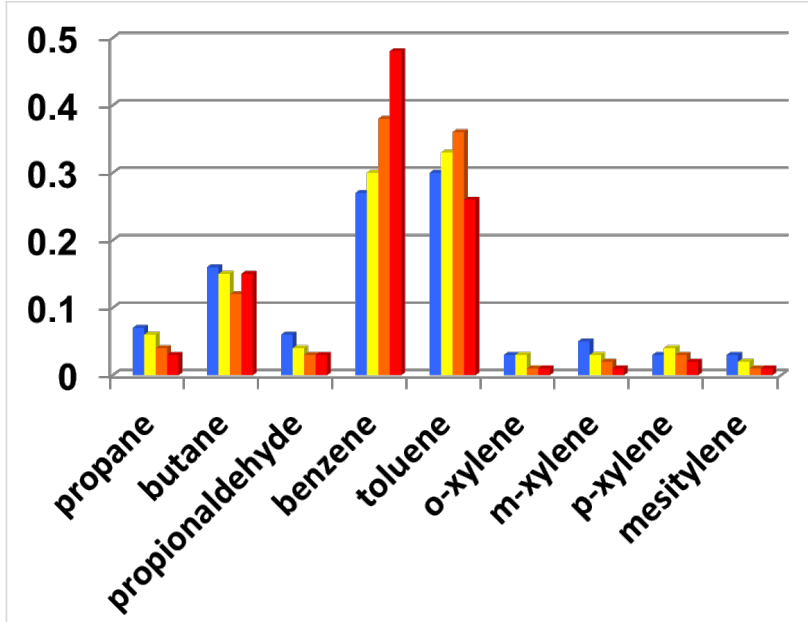

Figure 7: Product selectivities as a function of temperature: blue: $440{ }^{\circ} \mathrm{C}$, yellow: $480{ }^{\circ} \mathrm{C}$, orange: $500{ }^{\circ} \mathrm{C}$, red: $520^{\circ} \mathrm{C}$. The experimental error from three repetitions is $+/-0.03$ for butane, benzene and toluene, and 0.01 for all other identified reaction products.

bar, one cold water cooled jacketed condenser on the middle neck, one septum and one temperature probe on each of the outer necks is charged with $60 \mathrm{~mL}$ 1-octadecene (ODE), $0.9 \mathrm{~mL}$ oleylamine and $0.831 \mathrm{~g}$ hexadecylammonium hydrochloride $(\mathrm{HDA} \cdot \mathrm{HCl})$. The reaction system was connected to a Schlenk line through the top of the jacketed condenser. The reaction mixture was degassed at $120{ }^{\circ} \mathrm{C}$ for 30 min under vigorous stirring. After being refilled with argon, the reaction mixture was heated to $180{ }^{\circ} \mathrm{C}$. Three portions of $0.7 \mathrm{~mL} \mathrm{Fe}(\mathrm{CO})_{5}$ were injected into the reaction mixture via a syringe every $20 \mathrm{~min}$. The reaction mixture was kept at $180{ }^{\circ} \mathrm{C}$ for another $40 \mathrm{~min}$ after the last injection, and allowed to cool to room temperature. The supernatant was decanted, and the iron nanoparticles accumulated on the magnetic stir bar were washed with hexane $(5 \times$ $10 \mathrm{~mL})$ and ethanol $(5 \times 10 \mathrm{~mL})$. The product was then dried in vacuum. Based on iron, the yield of the reaction was $95 \%$.

\section{Catalytic reduction of $\mathrm{CO}_{2} / \mathrm{H}_{2}$ mixtures to aromatic hydrocarbons}

The $\mathrm{CO}_{2} / \mathrm{H}_{2}$ mixture $(1: 1 \mathrm{~mol} / \mathrm{mol})$ was heated for $4 \mathrm{~h}$ in a tubular reactor $(d=20 \mathrm{~mm})$ containing $50 \mathrm{mg}$ of iron nanocata- lyst in a porcelain microvessel in a quartz reaction tube (inner diameter $=0.80 \mathrm{~cm}, l=40 \mathrm{~cm}$ ). After the reaction mixture was allowed to cool down to $\mathrm{rt}$, the gas phase was analyzed by using GC-MS. The reaction temperature was between $380{ }^{\circ} \mathrm{C}$ and $520{ }^{\circ} \mathrm{C}$.

GC-MS analysis was carried out on an Agilent Technologies 7890A GC/5975C VL MSD with triple-axis detector using a HP5 capillary column. The compounds were identified by comparing their MS spectra with the standards in the Wiley data base, as well as by co-injection.

Powder X-ray diffraction (XRD) patterns were obtained on a Bruker D8 X-ray diffractometer with $\mathrm{Cu} \mathrm{K} \alpha$ radiation.

Transmission electron microscopy (TEM): Sample preparation and data collection are similarly described in a previous paper [70]. Briefly, samples were prepared by suspending the catalyst in ethanol and agitating in an ultrasonic bath for 15 min. A catalyst sample $(10 \mu \mathrm{L})$ was placed onto copper mesh grid with lacey carbon film. The wet grids were allowed to air-dry for several minutes prior to being examined under TEM. The catalyst particle size and morphology were examined by bright-field and dark-field transmission electron microscopy (TEM) using an FEI Technai $\mathrm{G}_{2}$ transmission electron microscope at an electron acceleration voltage of $200 \mathrm{kV}$. High resolution images were captured using a standardized, normative electron dose and a constant defocus value from the carbon-coated surfaces.

X-ray photoelectron spectroscopy (XPS): Sample preparation and data collection are similarly described in a previous paper [71]. Data was recorded with a Perkin-Elmer PHI 5400 electron spectrometer using acrochromatic $\mathrm{Al} \mathrm{K} \alpha$ radiation $(1486.6 \mathrm{eV})$. Analysis was carried out under vacuum $(p<$ $5 \cdot 10^{-9}$ Torr) and heated to $120{ }^{\circ} \mathrm{C}$ to remove any adsorbed molecules on the surface. The XPS binding energies were measured with a precision of $0.025 \mathrm{eV}$. The analyzer pass energy was set to $17.9 \mathrm{eV}$, the contact time was $50 \mathrm{~ms}$, and the area scanned was $4 \mathrm{~mm}^{2}$.

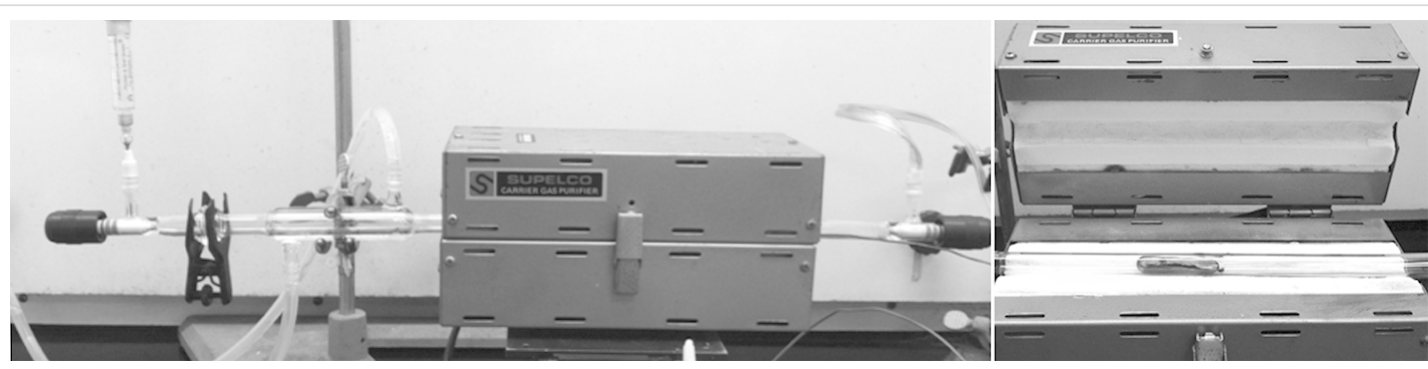

Figure 8: Tubular reactor used in the catalytic reduction reaction. 


\section{Conclusion}

We have obtained evidence for the formation of aromatic hydrocarbons (benzene, toluene, xylenes and mesitylene) from carbon dioxide and hydrogen mixtures at $1 \mathrm{~atm}$ on $\mathrm{Fe} / \mathrm{Fe}_{3} \mathrm{O}_{4}$ nanocatalysts. A minor fraction of aliphatic hydrocarbons is formed as well. This finding offers a viable pathway towards the direct and efficient formation of hydrocarbon mixtures that are suitable as chemical starting materials and high-quality biofuels from $\mathrm{CO}_{2}$ and hydrogen. This technology is, principally compatible with solar heat and hydrogen technology and has the potential to mitigate the impacts of global warming by making use of the existing distribution technology for gasoline.

\section{Supporting Information}

$\mathrm{CO}_{2}$ conversion data at $400{ }^{\circ} \mathrm{C}$, characterization of all relevant intermediates and products by $\mathrm{GC}-\mathrm{MS}$, and XRD analysis of the catalyst before and after catalysis are supplied as Supporting Information.

\section{Supporting Information File 1}

Additional experimental data.

[http://www.beilstein-journals.org/bjnano/content/ supplementary/2190-4286-5-88-S1.pdf]

\section{Acknowledgements}

This material is based upon work supported by the National Science Foundation under Award No. EPS-0903806 and matching support from the State of Kansas through Kansas Technology Enterprise Corporation.

\section{References}

1. Mazur, A. Hum. Ecol. Rev. 2009, 16, 17.

2. Annual Energy Review 2009; U.S. Energy Information Administration: Washington, DC, 2010; Tables 12.2-12.4, pp 349-353.

3. Dhandapani, B.; Oyama, S. T. Appl. Catal., B: Environ. 1997, 11, 129. doi:10.1016/S0926-3373(96)00044-6

4. Song, C. Catal. Today 2006, 115, 2. doi:10.1016/j.cattod.2006.02.029

5. Jessop, P. G.; Joó, F.; Tai, C.-C. Coord. Chem. Rev. 2004, 248, 2425. doi:10.1016/j.ccr.2004.05.019

6. Cokoja, M.; Bruckmeier, C.; Rieger, B.; Herrmann, W. A.; Kühn, F. E. Angew. Chem., Int. Ed. 2011, 50, 8510. doi:10.1002/anie.201102010

7. Torres Galvis, H. M.; Bitter, J. H.; Khare, C. B.; Ruitenbeek, M.; Dugulan, A. I.; de Jong, K. P. Science 2012, 335, 835. doi:10.1126/science.1215614

8. Nowotny, J.; Sorrell, C. C.; Sheppard, L. R.; Bak, T. Int. J. Hydrogen Energy 2005, 30, 521. doi:10.1016/j.ijhydene.2004.06.012

9. Miller, E. L. Solar Hydrogen Production by Photoelectrochemical Water Splitting: The Promise and Challenge. In On Solar Hydrogen \& Nanotechnology; Vayssieres, L., Ed.; John Wiley \& Sons: Chichester, UK, 2009; pp 3-35. doi:10.1002/9780470823996.ch1
10. Bora, D. K.; Braun, A.; Constable, E. C. Energy Environ. Sci. 2013, 6, 407. doi:10.1039/C2EE23668K

11. Stowe, R. A.; Russell, W. W. J. Am. Chem. Soc. 1954, 76, 319. doi:10.1021/ja01631a001

12. Dwyer, D. J.; Somorjai, G. A. J. Catal. 1978, 52, 291. doi:10.1016/0021-9517(78)90143-4

13. Prasad, P. S. S.; Bae, J. W.; Jun, K.-W.; Lee, K.-W. Catal. Surv. Asia 2008, 12, 170. doi:10.1007/s10563-008-9049-1

14. Niemelä, M.; Nokkosmäki, M. Catal. Today 2005, 100, 269. doi:10.1016/j.cattod.2004.09.061

15. Herranz, T.; Rojas, S.; Pérez-Alonso, F. J.; Ojeda, A.; Terreros, P.; Fierro, J. L. G. Appl. Catal., A 2006, 311, 66. doi:10.1016/j.apcata.2006.06.007

16. Ning, W. S.; Koizumi, N.; Yamada, M. Energy Fuels 2009, 23, 4696. doi:10.1021/ef900428t

17. Lee, J.-F.; Chern, W.-S.; Lee, M.-D.; Dong, T.-Y. Can. J. Chem. Eng. 1992, 70, 511. doi:10.1002/cjce.5450700314

18. Dry, M. E.; Shingles, T.; Boshoff, L. J.; Oosthuizen, G. J. J. Catal. 1969, 15, 190. doi:10.1016/0021-9517(69)90023-2

19. Dorner, R. W.; Hardy, D. R.; Williams, F. W.; Willauer, H. D. Appl. Catal., A 2010, 373, 112. doi:10.1016/j.apcata.2009.11.005

20. Xu, L.; Wang, Q.; Liang, D.; Wang, X.; Lin, L.; Cui, W.; Xu, Y. Appl. Catal., A 1998, 173, 19. doi:10.1016/S0926-860X(98)00141-0

21. Abbott, J.; Clark, N. J.; Baker, B. G. Appl. Catal. 1986, 26, 141. doi:10.1016/S0166-9834(00)82547-6

22. Ando, H.; Xu, Q.; Fujiwara, M.; Matsumura, Y.; Tanaka, M.; Souma, Y. Catal. Today 1998, 45, 229. doi:10.1016/S0920-5861(98)00220-X

23. Yan, S.-R.; Jun, K.-W.; Hong, J.-S.; Choi, M.-J.; Lee, K.-W. Appl. Catal., A: Gen. 2000, 194-195, 63. doi:10.1016/S0926-860X(99)00354-3

24. Zhao, G.; Zhang, C.; Qin, S.; Xiang, H.; Li, Y. J. Mol. Catal. A: Chem. 2008, 286, 137. doi:10.1016/j.molcata.2008.02.019

25. Lee, S.-C.; Jang, J.-H.; Bee, B.-Y.; Kang, M.-C.; Kang, M.; Choung, S.-J. Appl. Catal., A 2003, 253, 293. doi:10.1016/S0926-860X(03)00540-4

26. Chan, B.; Radom, L. J. Am. Chem. Soc. 2006, 128, 5322. doi:10.1021/ja0602492

27. Chan, B.; Radom, L. J. Am. Chem. Soc. 2008, 130, 9790. doi:10.1021/ja800840q

28. Kuei, C.-K.; Lee, M.-D. Can. J. Chem. Eng. 1991, 69, 347. doi:10.1002/cjce.5450690142

29. Moshfegh, A. Z. J. Phys. D: Appl. Phys. 2009, 42, 233001. doi:10.1088/0022-3727/42/23/233001

30. Somorjai, G. A.; Frei, H.; Park, J. Y. J. Am. Chem. Soc. 2009, 131, 16589. doi:10.1021/ja9061954

31. Klabunde, K. J.; Richards, R. M. Nanoscale Materials in Chemistry; John Wiley \& Sons, Inc.: USA, 2009. doi:10.1002/9780470523674

32. Tao, F.; Dag, S.; Wang, L.-W.; Liu, Z.; Butcher, D. R.; Bluhm, H.; Salmeron, M.; Somorjai, G. A. Science 2010, 327, 850. doi:10.1126/science.1182122

33. Tao, F.; Grass, M. E.; Zhang, Y.; Butcher, D. R.; Renzas, J. R.; Liu, Z.; Chung, J. Y.; Mun, B. S.; Salmeron, M.; Somorjai, G. A. Science 2008, 322, 932. doi:10.1126/science. 1164170

34. Huber, D. L. Small 2005, 1, 482. doi:10.1002/smll.200500006

35. Hao, R.; Xing, R.; Xu, Z.; Hou, Y.; Gao, S.; Sun, S. Adv. Mater. 2010, 22, 2729. doi:10.1002/adma.201000260

36. Peng, S.; Kim, J.; Sun, S. Annu. Rev. Nano Res. 2009, 3, 275. doi:10.1142/9789814280525_0006

37. Chaudhuri, R. G.; Paria, S. Chem. Rev. 2012, 112, 2373. doi:10.1021/cr100449n 
38. Park, J.; Lee, E.; Hwang, N.-W.; Kang, M.; Kim, S. C.; Hwang, Y.; Park, J.-G.; Noh, H.-J.; Kim, J.-Y.; Park, J.-H.; Hyeon, T. Angew. Chem., Int. Ed. 2005, 44, 2872. doi:10.1002/anie.200461665

39. Kim, D.; Lee, N.; Park, M.; Kim, B. H.; An, K.; Hyeon, T. J. Am. Chem. Soc. 2009, 131, 454. doi:10.1021/ja8086906

40. Sun, S.; Zeng, H.; Robinson, D. B.; Raoux, S.; Rice, P. M.; Wang, S. X.; Li, G. J. Am. Chem. Soc. 2004, 126, 273. doi:10.1021/ja0380852

41. Song, H.-M.; Wei, Q.; Ong, Q. K.; Wei, A. ACS Nano 2010, 4, 5163. doi:10.1021/nn101202h

42. Lacroix, L.-M.; Ho, D.; Sun, S. Curr. Top. Med. Chem. 2010, 10, 1184. doi:10.2174/156802610791384207

43. Kim, B. H.; Lee, N.; Kim, H.; An, K.; Park, Y. I.; Choi, Y.; Shin, K.; Lee, Y. G.; Kwon, S. G.; Na, H. B.; Park, J.-G.; Ahn, T.-Y.; Kim, Y.-W.; Moon, W. K.; Choi, S. H.; Hyeon, T. J. Am. Chem. Soc. 2011, 133, 12624. doi:10.1021/ja203340u

44. Kievit, F. M.; Zhang, M. Acc. Chem. Res. 2011, 44, 853. doi:10.1021/ar2000277

45. Guo, S.; Zhang, S.; Sun, X.; Sun, S. J. Am. Chem. Soc. 2011, 133, 15354. doi:10.1021/ja207308b

46. Wang, C.; van der Vliet, D.; More, K. L.; Zaluzec, N. J.; Peng, S.; Sun, S.; Daimon, H.; Wang, G.; Greeley, J.; Pearson, J.; Paulikas, A. P.; Karapetrov, G.; Strmcnik, D.; Markovic, N. M.; Stamenkovic, V. R. Nano Lett. 2011, 11, 919. doi:10.1021/nl102369k

47. Mazumder, V.; Chi, M.; More, K. L.; Sun, S. J. Am. Chem. Soc. 2010, 132, 7848. doi:10.1021/ja1024436

48. Kim, J.; Lee, Y.; Sun, S. J. Am. Chem. Soc. 2010, 132, 4996. doi:10.1021/ja1009629

49. Lacroix, L.-M.; Huls, N. F.; Ho, D.; Sun, X.; Cheng, K.; Sun, S. Nano Lett. 2011, 11, 1641. doi:10.1021/nl200110t

50. Ahn, B. K.; Wang, H.; Robinson, S.; Shrestha, T. B.; Troyer, D. L.; Bossmann, S. H.; Sun, X. S. Green Chem. 2012, 14, 136. doi:10.1039/c1gc16043e

51. de Smit, E.; van Schooneveld, M. M.; Cinquini, F.; Bluhm, H.; Sautet, P.; de Groot, F. M. F.; Weckhuysen, B. M. Angew. Chem., Int. Ed. 2011, 50, 1584. doi:10.1002/anie.201005282

52. Povstugar, V. I.; Mikhailova, S. S. Ultrathin protective organic layers on iron surfaces. Handbook of Surfaces and Interfaces of Materials; Academic Press, 2001; Vol. 4, pp 561-604. doi:10.1016/b978-012513910-6/50057-8

53. Shroff, M. D.; Kalakkad, D. S.; Coulter, K. E.; Koehler, S. D.; Harrington, M. S.; Jackson, N. B.; Sault, A. G.; Datye, A. K. J. Catal. 1995, 156, 185. doi:10.1006/jcat.1995.1247

54. Leveneur, J.; Waterhouse, G. I. N.; Kennedy, J.; Metson, J. B.; Mitchell, D. R. G. J. Phys. Chem. C 2011, 115, 20978. doi:10.1021/jp206357c

55. Wiberg, E. Inorganic Chemistry; Walter de Gruyter: Berlin, 2001; p 1439.

56. Wambach, J.; Baiker, A.; Wokaun, A. Phys. Chem. Chem. Phys. 1999, 1, 5071. doi:10.1039/a904923a

57. López, C.; Corma, A. ChemCatChem 2012, 4, 751. doi:10.1002/cctc.201200178

58. Kammula, S.; Shevlin, P. B. J. Am. Chem. Soc. 1973, 95, 4441. doi:10.1021/ja00794a061

59. Kybett, B. D.; Johnson, G. K.; Barker, C. K.; Margrave, J. L. J. Phys. Chem. 1965, 69, 3603. doi:10.1021/j100894a060

60. McLafferty, F. W., Ed. Wiley Registry of Mass Spectral Data; John Wiley and Sons. doi:10.1002/9780470175217
61. Yang, T.; Wen, X.-d.; Ren, J.; Li, Y.-W.; Wang, J.-g.; Huo, C.-f. J. Fuel Chem. Technol. 2010, 38, 121-128. doi:10.1016/S1872-5813(10)60024-2

62. Stanka, B.; Hebenstreit, W.; Diebold, U.; Chambers, S. A. Surf. Sci. 2000, 448, 49. doi:10.1016/S0039-6028(99)01182-6

63. Ceballos, S. F.; Mariotto, G.; Jordan, K.; Murphy, S.; Seoighe, C.; Shvets, I. V. Surf. Sci. 2004, 548, 106. doi:10.1016/j.susc.2003.10.041

64. Mariotto, G.; Murphy, S.; Shvets, I. V. Phys. Rev. B: Condens. Matter Mater. Phys. 2002, 66, 245426.

65. Condon, N. G.; Murray, P. W.; Leibsle, F. M.; Thornton, G.; Lennie, A. R.; Vaughan, D. J. Surf. Sci. 1994, 310, L609. doi:10.1016/0039-6028(94)91360-9

66. Slayden, S. W.; Liebman, J. F. Chem. Rev. 2001, 101, 1541. doi:10.1021/cr990324+

67. de Jong, K. P. Catal. Sci. Ser. 1999, 1, 57. doi:10.1142/9781848160613_0004

68. Wright, F. J.; Richard, M. A.; Pirkle, J. C., Jr. Process for producing aromatic hydrocarbons from carbon monoxide and water. US Patent US000004565831A, Jan 21, 1986.

69. Friedrichs, G.; Wagner, H. G. Z. Phys. Chem. 1998, 203, 1. doi:10.1524/zpch.1998.203.Part_1_2.001

70. Jin, X.; Roy, D.; Thapa, P. S.; Subramaniam, B.; Chaudhari, R. V. ACS Sustainable Chem. Eng. 2013, 1, 1453. doi:10.1021/sc400189d

71. Nguyen, P.; Li, J.; Sreeprasad, T. S.; Jasuja, K.; Mohanty, N.; Ikenberry, M.; Hohn, K.; Shenoy, V. B.; Berry, V. Small 2013, 9, 3823. doi:10.1002/smll.201300857

\section{License and Terms}

This is an Open Access article under the terms of the Creative Commons Attribution License (http://creativecommons.org/licenses/by/2.0), which permits unrestricted use, distribution, and reproduction in any medium, provided the original work is properly cited.

The license is subject to the Beilstein Journal of Nanotechnology terms and conditions: (http://www.beilstein-journals.org/bjnano)

The definitive version of this article is the electronic one which can be found at: $\underline{\text { doi:10.3762/bjnano. } 5.88}$ 